\title{
PET VIGILÂNCIA EM SAÚDE: RELATO DE UMA EXPERIÊNICA NA EXTENSÃO UNIVERSITÁRIA
}

\author{
Elis Ângela Batistella \\ Universidade Federal de Santa Catarina \\ elisbatistella@hotmail.com
}

\begin{abstract}
Resumo
O objetivo deste artigo é relatar a experiência vivenciada no Programa de Educação Tutorial em Vigilância em Saúde -PET Saúde, desenvolvido entre 2010 a 2012 na Universidade Federal de Santa Catarina. Foram planejados encontros semanais para debates em saúde no início do projeto, além de atividades práticas a serem realizadas fora da universidade. As atividades nauniversidade consistiram de dinâmicas de grupo, apresentações e debates, e o trabalho de campo deu-se por meio do acompanhamento do processo dos serviços no Laboratório Central e Diretoria de Vigilância Epidemiológica de Santa Catarina. A transdisciplinaridade e o compartilhamento de saberes entre estudantes do Centro de Ciências da Saúde com os serviços acompanhados foram evidentes. Esta experiência oportunizou uma troca de conhecimentos para além da sala de aula tanto com relação aos conceitos de saúde quanto para o processo de trabalho nas esferas da vigilância em saúde.

Palavras-chave: Extensão Universitária. Ensino Universitário. Transdisciplinaridade.
\end{abstract}

\section{PET HEALTH SURVILLANCE: REPORT OF AN ACADEMIC EXTENSION EXPERIENCE}

\begin{abstract}
The aim of this article is to report an experience lived during the PET health survillance extension program, developed between 2010 and 2012, at the Federal University of Santa Catarina. There were planned weekly meetings to debate on health subject at the beggining of the process, together with practical activities to be performed outside of the university. At the university, the activities consisted of groups of dynamics, debates and presentations, and the field activity was comprised by means of following the work processess in the "Laboratório Central and the Diretoria de Vigilância Epidemiológica de Santa Catarina". The transdisciplinarity and the knowledge sharing amongst the students from the university health center with the accompained services were evident. This experience provided an opportunity to exchange savvies beyond the classroom in relation to health concepts and to the work process on the health survillance scope.
\end{abstract}

Keywords: Academic Extention. University Teaching. Transdisciplinarity.

\section{PET VIGILANCIA EN SALUD: RELATO DE UNA EXPERIENCIA EN LA EXTENSIÓN UNIVERSITARIA}

\begin{abstract}
Resumen
El objetivo de este artículo es relatar la experiencia vivida en el programa de extensión PET vigilancia en salud, desarrollado entre 2010 a 2012 en la Univesidad Federal de Santa Catarina. Se planearon encuentros semanales para debates en salud al inicio del proyecto, además de actividades prácticas a ser realizadas fuera de la universidad. Las actividades en la universidad consistieron de dinámicas de grupo, presentaciones y debates y el trabajo de campo se dio por medio del seguimiento del proceso de los servicios en el Laboratorio Central y la Dirección de Vigilancia Epidemiológica de Santa Catarina. La transdisciplinariedad y el intercambio de conocimientos entre estudiantes del Centro de Ciencias de la Salud con los servicios acompañados fueron evidentes. Esta experiencia permitio un intercambio de conocimientos más allá del aula en relación a los conceptos de salud y al proceso de trabajo en las esferas de la vigilancia en salud.
\end{abstract}

Palabras clave: Extensión Universitaria. Enseñanza Universitaria. Transdisciplinariedad. 
Pet vigilância em saúde: relato de uma experiênica na extensão universitária

\section{INTRODUÇÃO}

A extensão universitária teve seu conceito submetido a várias alterações ao longo da história das universidades brasileiras, passando por diversas matizes e diretrizes conceituais. Ela representa uma ferramenta para o aprofundamento contínuo e sistemático da universidade em seu papel fundamental de comprometimento com a transformação social, aproximando a construção e transmissão de saberes a quem se destina, tomando o cuidado para retificar, neste trajeto, as barreiras que transpõem a apropriação social do conhecimento, das ciências e tecnologias (PAULA, 2013).

Segundo Queiroz e Dourado (2009), no contexto do ensino odontológico, a extensão universitária traz a possibilidade de modificar o processo da transmissão vertical do conhecimento e do modelo biomédico de atuação profissional, dando abertura para que os estudantes articulem com a comunidade, no intuito de observar suas necessidades e aplicar seus conhecimentos na transformacão daquela realidade. Já em 1962, a Organização Mundial da Saúde propôs que a escola de odontologia teria de adaptar-se ao meio em que seus estudantes executam a profissão, e também capacitá-los a influir nas atitudes da população e da administração pública quanto à higiene e prevenção, de modo a facilitar o alcance do objetivo de estender os benefícios da saúde bucal ao mundo inteiro (OMS, 1962, p.14).

Deste modo, a extensão universitária apresenta uma conexão entre os conhecimentos produzidos no ambiente acadêmico com experiências e culturas locais e, da mesma forma, destas para com o ambiente universitário. Este processo oportuniza um caminho de mudanças no meio, e transforma seu engajamento com as demais áreas acadêmicas, a saber, o ensino e a pesquisa. A extensão como uma ferramenta para a transformação, empoderamento e educação, desenvolvida de modo articulado com a comunidade, permite o enriquecimento do estudante de extensão bem como dos demais membros e do local envolvido no processo. Sua inter e transdisciplinaridade intrínseca oportuniza ao estudante de odontologia o desenvolvimento de um campo imenso que somente na sala de aula não poderia ser explorado, daí sua importância.

$\mathrm{Na}$ visão do extensionista, de acordo com o que foi vivenciado no projeto, o PET é um segmento do papel universitário que traz possibilidade de trazer e levar conhecimento para fora da sala de aula. É um projeto que serve como uma ponte entre a universidade e a comunidade, abrindo uma porta aos alunos para buscarem a realidade das demandas existentes, as quais muitas vezes podem ser deixadas em segundo plano e ser pouco debatidas ao longo dos anos nos cursos de

Extensio: R. Eletr. de Extensão, ISSN 1807-0221 Florianópolis, v. 15, n. 28, p. 161-167, 2018. 
Pet vigilância em saúde: relato de uma experiênica na extensão universitária

graduação. Assim, este trabalho tem por objetivo relatar a experiência desenvolvida em um programa de extensão universitária durante os anos de graduação na odontologia.

\section{MATERIAIS E MÉTODOS}

Entre agosto de 2010 a junho de 2012, na Universidade Federal de Santa Catarina (UFSC), foi realizado o PET Vigilância em Saúde. As atividades de campo desenvolveram-se no Laboratório Central (LACEN- Florianópolis/SC) e na Diretoria de Vigilância Epidemiológica do estado (DIVE$\mathrm{SC})$.

Os coordenadores do projeto foram a Professora Josimari Telino Lacerda e o Professor Erasmo Benício Santos de Moraes Trindade, ambos professores no Centro de Ciências da Saúde da UFSC. Os demais membros do projeto de extensão provinham de diferentes cursos de graduação do centro de ciências da saúde, a saber, farmácia, medicina, nutrição e odontologia.

Inicialmente foram planejados e executados encontros semanais, nos quais debateu-se o conceito de saúde e assuntos ligados às diversas áreas de atuação profissional. Em cada encontro um estudante trazia um artigo para discutir com o grupo maior, e assim diversos conhecimentos transpassaram nossos campos de competência profissional.

Posteriormente, os coordenadores nos ensinaram alguns recursos básicos do programa Excel ${ }^{\circledR}$ e também nos demonstraram como utilizar os principais Sistemas de Informação em Saúde para a coleta de dados em dois grandes grupos: 1) doenças cardiovasculares e neoplasias; 2) Doenças Sexualmente Transmissíveis (DSTs)/Aids e síndrome metabólica.

Além disso, os estudantes foram subdivididos para acompanhar as atividades no LACEN e na DIVE-SC, auxiliando nos processos desempenhados nestas instâncias e tentando engajar seus conhecimentos de epidemiologia dentro das atividades desempenhadas por estes serviços.

No LACEN, os estudantes acompanharam todo o trâmite do processo de exames que eram realizados, como por exemplo, o teste do pezinho, que avalia crianças recém-nascidas de todo o estado de Santa Catarina, os testes para detecção de infecções virais e atividades de rotina do laboratório. Participaram também da elaboração de manuais para controle de doenças endêmicas e transmitidas por vetores.

Na DIVE, os extensionistas puderam acompanhar a elaboração de estratégias para prevenção das DSTs a serem efetuadas principalmente em escolas do estado e secretarias municipais de saúde, 
Pet vigilância em saúde: relato de uma experiênica na extensão universitária

elaborar cartilhas informativas quanto a doenças oportunistas que se manifestam na boca em pacientes $\mathrm{HIV}+$, participar do trâmite de compra e distribuição de testes rápido do HIV e de fórmula infantil para bebês filhos de mães soropositivas que não podiam amamentar para não passar o vírus ao filho.

Ao final do programa, os estudantes novamente reuniam-se na universidade, apresentado ao grande grupo as experiências e aprendizados compartilhados ao longo da trajetória, e também trazendo os problemas encontrados neste processo, tanto nos serviços acompanhados quanto na própria atividade de extensão, que poderiam ser trabalhados para um futuro programa de extensão ter ainda mais qualidade.

\section{RESULTADOS E ANÁLISES}

Foram necessários três encontros para debater os mais diversos conceitos da palavra "saúde", trazendo desde as definições clássicas da Organização Mundial da Saúde até o entendimento próprio de cada participante. Em uma dinâmica de grupo, cada estudante de extensão escreveu uma só palavra que considerava conceituar o termo saúde. Algumas palavras escritas foram: bem-estar, equilíbrio, sorriso, adaptação, harmonia, conjunto. Para cada palavra, cada um trouxe à tona o que pensava sobre aquilo. Por exemplo: para a palavra "equilíbrio", a pessoa explicava o porquê de tê-la escolhido, e o grupo poderia argumentar ou levantar questionamentos, tais como: “o equilíbrio só é possível com a morte" ou "naturalmente não estamos em equilíbrio na vasta maioria dos momentos, o que não significa necessariamente que não temos saúde”.

Uma das palavras que mais chamou atenção nesta dinâmica foi “adaptação". A capacidade de adaptar-se mesmo a um processo de doença, a um contexto difícil, ou a outra esfera que interfira na saúde da pessoa, permite que ela floreça e desfrute do viver. Esta ressignificação de saúde vai para além de um conceito de completo bem-estar que é algo inexequível e inatingível. Ele implica também em a pessoa ter um processo ativo sobre sua condição e na forma como vai enfrentar seus obstáculos e seguir adiante.

Observou-se que a visão de saúde como a ausência de doença transpassa o campo da odontologia. Estudantes de outras áreas da saúde também traziam estes resquícios conceituais em suas falas. Isso foi discutido no grande grupo, e a importância de que "não tratamos doenças, e sim, 
Pet vigilância em saúde: relato de uma experiênica na extensão universitária

pessoas" foi cruscial para a internalização do nosso papel no processo de prevenção e promoção de saúde.

Outro fator que inicialmente estava presente mas foi muito bem trabalhado ao longo dos encontros, foi a separação da ciências em disciplinas, o que na sociedade é julgado separadamente como mais ou menos importante. Assim, discutiu-se como houve a necessidade de subdividir o campo da saúde em áreas, porém, naturalmente, a atuação em saúde requer uma visão multidisciplinar. Sendo assim, não há profissão mais ou menos importante, eles se complementam e devem caminhar juntas.

Para seguir com nossas atividades e ir à campo, nossos coordenadores ensinaram os principais Sistemas de Informação em Saúde, e com este conhecimento foi possível acompanhar as atividades nos serviços de vigilância epidemiológica (DIVE-SC) e em um laboratório que presta serviços ao sistema público de saúde para todo o estado (LACEN).

$\mathrm{Na}$ atividade de campo, inicialmente foi feito o acompanhamento das atividades para conseguir entender a dinâmica de trabalho. $\mathrm{Na}$ área da vigilância em saúde, acompanhou-se as estratégias para prevenção de agravos nas cidades de Santa Catarina, o processo de distribuição de testes rápidos para detecção do HIV em algumas unidades de saúde, a redistribuição de fórmula infantil para filhos de HIV soropositivos, e as campanhas de redução de danos.

Algo importante no projeto foi o estudo do que é a redução de danos. O entendimento de que existe um risco de algumas doenças acontecerem e a necessidade de intervir ativamente foi algo que colocou em questão até mesmo valores pessoais. Foi difícil assimilar que oferecer um kit para auto-injeção de drogas poderia ser uma medida efetiva de prevenção em saúde. Porém, ao debatermos a estratégia de entregar kits, foi possível entender que desta forma reduzia-se o risco de transmissão de hepatite viral e HIV e oportunizava-se a abertura de uma porta que leva à aproximação com o usuário para discutir os riscos do uso de drogas e as possibilidades para abandonar o vício. Funciona de um modo semelhante à distribuição de preservativos nas unidades de saúde. As pessoas naturalmente se relacionam, e, deixando a moralidade e os julgamentos à parte, é mais efetivo em termos de saúde pública, distribuir preservativos do que tratar um indivíduo com HIV ao longo de uma vida inteira.

Uma atividade realizada e que foi ofertada para a comunidade foi a criação de um folder explicativo sobre as doenças sexualmente transmissíveis e as manifestações bucais de algumas DSTs. Estas informações representam uma forma de apropriação social do conhecimento que muitas vezes somente é oportunizado nas salas de aula e fica restrito aos profissionais da saúde. Todo este material 
Pet vigilância em saúde: relato de uma experiênica na extensão universitária

e os conteúdos foram debatidos com os profissionais dos serviços, os quais também provinham de diversas áreas de formação; além da área da saúde, haviam profissionais das ciências exatas e humanas.

Pela grande variedade de saberes presentes nos serviços, foi possível aprender como o sistema de saúde é complexo, e também permitiu a apreciação de diversos obstáculos que atrapalham na efetivação do cuidado em saúde. A principal dificuldade trazida pelos estudantes de extensão foi o excesso de burocracia nos trâmites desempenhados dentro do LACEN e da DIVE. Além disso, a falta da utilização das informações oportunizadas pelos Sistemas de Informação em Saúde no planejamento de estratégias de promoção e prevenção encaressem medidas e despendem dinheiro público para necessidades que muitas vezes não são prioridade para alguns locais. Além disso, mencionou-se que muitos representantes ocupando cargos por indicação não tinham formação para tanto, o que desfavorecia o processo de gestão e planejamento em saúde.

Com relação ao projeto de extensão, o principal desafio relatado pelos extensionistas foi a questão de disponibilidade de tempo, uma vez que a carga horária das disciplinas dos cursos era significativamente elevada, e para participar do PET era necessário dispôr de 20 horas de dedicação semanal no projeto.

Ainda assim, foi possível explorar um mundo além da universidade, e ver que este universo não está isolado, mas sim, está diretamente relacionado à formação profissional na área da saúde. O ideal "universidade: ensino, pesquisa e extensão" ainda não está disponível a todos os acadêmicos. Neste caso PET vigilância em saúde representou uma oportunidade de expandir horizontes para os estudantes que participaram do projeto. O grupo de extensão possibilitou transformações importantes na formação de cada estudante, e os serviços também tiveram a oportunidade de transformar seus conhecimentos com os participantes, trazendo uma nova perspectiva também às instituições que receberam os extensionistas.

\section{CONSIDERAÇÕES FINAIS}

A extensão universitária representa uma conexão entre os conhecimentos produzidos no ambiente acadêmico com experiências e culturas locais e, da mesma forma, destas para com o ambiente universitário. Ela seria ainda mais transformadora se oportunizasse todo estudante universitário com uma vaga, um convite a novas experiências e a aplicar seus conhecimentos na transformação da sua realidade. A extensão acadêmica, por meio do PET vigilância em saúde,

Extensio: R. Eletr. de Extensão, ISSN 1807-0221 Florianópolis, v. 15, n. 28, p. 161-167, 2018. 
Pet vigilância em saúde: relato de uma experiênica na extensão universitária

permitiu um aprofundamento e ressignificação dos conhecimentos oportunizados em sala de aula, efetivando o papel importante da universidade em seu compromisso com a transformação social.

\section{REFERÊNCIAS}

ORGANIZAÇÃO MUNDIAL DA SÁUDE. La enseñanza de la odontologia. Genebra: OMS. (Série Informes Técnicos). 1962. 244 p.

PAULA, João Antônio de. A extensão universitária: história, conceito e propostas. Interfaces Revista de Extensão, Minas Gerais, v. 1, n. 1, p.5-23, jul. 2013.

QUEIROZ, Maria Goretti; DOURADO, Luiz Fernandes. O ensino da odontologia no Brasil: uma leitura com base nas recomendações e nos encontros internacionais da década de 1960. História, Ciências, Saúde - Manguinhos, Rio de Janeiro, v.16, n.4, out.-dez. 2009, p.1011-1026.

SERRANO, Rossana Maria Souto Maior. Conceitos de extensão universitária: um diálogo com Paulo Freire. 2008. Disponível em:

<http://www.prac.ufpb.br/copac/extelar/atividades/discussao/artigos/conceitos_de_extensao_uni versitaria.pdf $>$. Acesso em 30. mai. 2017. 